\title{
BC debates efficacy of physician incentives
}

$\mathrm{N}$ ew research claiming that incentives for family physicians in British Columbia haven't led to improved primary care is causing tension among the province's doctors and health policy analysts.

The study, published in Healthcare Policy, examined trends in access to primary care in the 12 years leading up to incentives rolled out by the General Practice Services Committee (GPSC) and the six years that followed.

The goal of the incentives is to encourage family physicians in the provision of "full service" and more accessible care that is better managed at the primary care level. Incentives include: $\$ 315$ extra per year per patient with two or more chronic illnesses, $\$ 1500$ quarterly for providing networked maternal care and $\$ 40$ per time spent conferencing with other providers in treating high-needs patients. Since the incentives were gradually rolled out beginning in 2003, the BC government has spent $\$ 700$ million on the program.

Despite these incentives, downward trends continued apace for the main access indicators studied, including physicians providing care outside office hours and in out-of-office settings, as well as a single physician providing the majority of a patient's care, the study found. For example, coauthor Kim McGrail, associate director of the Centre for Health Services and Policy Research at the University of British Columbia (UBC), says that those seeing patients in homes fell from $92 \%$ in 1992 to $76 \%$ in 2002, and then dropped to $55 \%$ in 2010.

"We would expect to see, maybe not a rebounding, but at least something that stops the decline," says McGrail.

A recent op-ed in the Kelowna Daily Courier by two of the study's authors sparked Dr. William Cavers, president of Doctors of $\mathrm{BC}$, to pen a response that highlighted the incentives program's successes while arguing the UBC study used "simplistic" data.

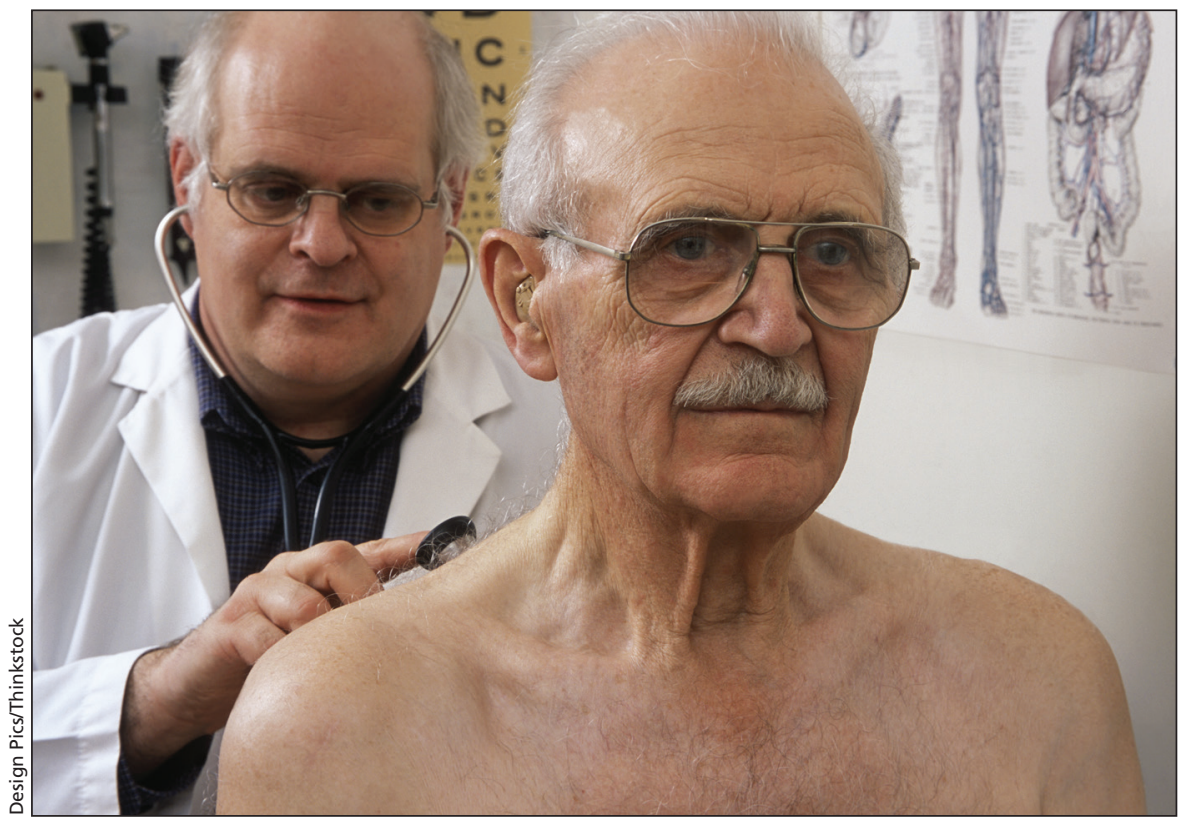

Despite financial incentives, downward trends seem to have continued for the main access indicators studied, including physicians providing care outside office hours and in out-of-office settings.

In an interview, Cavers says the study's an alysis was partly distorted by a misunderstanding that doctors scheduling office time over evenings and weekends bill under a special code, when they don't.

On a broader note, "the timeframe of the research doesn't really allow for us to capture any of the changes," Cavers says. The UBC researchers examined billing data up to the 2009-2010 year, while incentives were gradually rolled out between 2003 and 2009.

"There's inertia in the system when one is trying to turn it around," agrees Dr. Garey Mazowita, a family physician in Vancouver and committee member of the GPSC.

The GPSC was established in 2002 in response to a situation where "family doctors were not well reimbursed or well respected," he says. "At that time, I was quite surprised to meet with doctors who hadn't had holidays in two years."

Other studies, presented on the GPSC website, show benefits in costsavings and patient outcomes related to the incentives. But these studies were contracted by the GPSC and didn't control for differences in the patient populations whose doctors received incentives versus those who didn't, says Dr. Vanessa Brcic, a family physician and researcher at the UBC Department of Family Practice.

Virtually all studies comparing remuneration systems are limited by the reality that different payment models may attract different types of doctors or patient populations, says Dr. Robyn Tamblyn, scientific director of the Canadian Institutes of Health Research Institute of Health Services and Policy Research. "We can't randomize people to be paid one way or another."

In addition to questioning the incentives' efficacy, McGrail worries incentives could mean less team-based care in $\mathrm{BC}$ than other provinces. By making fee for service more attractive by adding incentives, the province is encouraging individual-led clinics and "closing off the opportunity to build interdisciplinary practices," like those in Ontario and Nova Scotia, she says. 
However, GPSC member Mazowita says the conversation about moving to more team-based care models can only happen now that payment and other reforms have improved a once-sour relationship between policy-makers and physicians. "We had to build on what physicians understood and trusted, and that happened to be fee for service."
But, he says, that doesn't mean fee for service will be pursued indefinitely. "There's no question that team-based models are the consuming interest right now [for the GPSC]," he says.

Such innovative collaborations may appeal more to new graduates. Brcic's 2012 survey published in Canadian Family Physician of 133 graduates of UBC's medical school found that $71 \%$ favoured salaried, capitation or blended payment models over fee for service. "There really is a divide between what younger and older doctors want." This same divide was recently written about in a $C M A J$ blog. - Wendy Glauser, Toronto, Ont.

CMAJ 2014. DOI:10.1503/cmaj.109-4863 